\title{
Exploring Collaborative Adaptive Management of Water Resources
}

\author{
Steve Light ${ }^{1}$, Wietske Medema ${ }^{1} \&$ Jan Adamowski ${ }^{1}$ \\ ${ }^{1}$ Department of Bioresource Engineering, McGill University, Quebec, Canada \\ Correspondence: Jan Adamowski, Department of Bioresource Engineering, McGill University, Ste Anne de \\ Bellevue, Quebec H9X 3V9, Canada. Tel: 1-514-398-7786. E-mail: jan.adamowski@mcgill.ca
}

\author{
Received: November 12, 2012 Accepted: February 18, 2013 Online Published: February 25, 2013 \\ doi:10.5539/jsd.v6n3p31 \\ URL: http://dx.doi.org/10.5539/jsd.v6n3p31
}

\begin{abstract}
A host of new and "wicked" problems are plaguing today's water resources and managers. The challenges and obstacles stemming from these problems are multidimensional, cumulative, and unprecedented and speak to the need for continuing to explore new approaches in water resources management and restoration efforts. This new class of interdependent problems is explored in this paper and some recently proposed ideas in collaborative adaptive management (CAM) are further developed to help address these types of "wicked" problems. It is argued that collaborative adaptive management, which combines the concepts of adaptive management and collaborative management, can help address the seemingly intractable technical, environmental and social problems inherent in complex social-ecological systems. Because it is important to highlight the importance of induction and emergent understanding under conditions of complexity, the concept of Ecological Policy Design is revisited as it relates to complex problem solving. Other concepts that are further explored and developed in this article include: project optimization that is based on devising composite solutions rather than attempting to "divide and conquer" individual subsystems; avoidance of "instability zones"; ecological and restoration efforts that are more "future responsive"; and the development of alternative hypotheses worthy of rapid prototyping through collaboration. Sustainable solutions are defined as those capable of governing and preserving the vitality of our waterways and the ecosystems that support them. To this end, we conclude that a more collaborative and adaptive approach to water management must be adopted if these types of solutions are to emerge.
\end{abstract}

Keywords: adaptive management, participation, water management, policy design

\section{Introduction}

Current paradigms and conventional approaches to water resources management have failed to respond to the wide range of stressors that continue to threaten our socio-ecological systems. From the Columbia River salmon recovery to the Everglades to the San Francisco Bay/Delta, it is clear that our current watershed management practices are inadequate; in fact an alarming number of river-related restoration efforts have outright failed. Many rivers, such as the Missouri River, serve a wide range of economic and environmental purposes: from water supply and flood protection to navigation and hydropower to ecosystem vitality. The diverse and often conflicting uses of such waterways create a host of multifaceted problems that have yet to be properly addressed. Not only are the institutional and agency responses to such problems inadequate, but the majority of waterway infrastructures and designs are as well. This is exemplified in Coastal Louisiana and its flawed approach to flood protection and ecological restoration that totally ignores the dominant influence of navigation in the Mississippi Delta. Unusual climatic conditions in 2005 exposed its piecemeal approach to levee construction and maintenance as well as the fractured federal and state governance system that neglected it. In other parts of the world, from Haiti to Cyprus to Australia, long-term shifts in weather patterns have created water resources conflicts, and these conflicts often bring overarching geo-political consequences, as evidenced by the chaotic state of drought-stricken northern Kenya.

A more nuanced and responsive approach to managing and protecting water resources is crucial in order to address the above described types of problems, as well as those related to negative synergies, rising energy costs, climate change, population increases, and decreasing water availability. Some key lessons have been learned regarding limitations and opportunities of different water management approaches through experimentation over the past few decades with both significant management paradigm shifts as well as massive public works to move, rationalize, conserve, and expand the use of freshwater through space and time (Engle et al., 2011): 
(1) A multitude of conflicting interests and pressures on water resources, decisions about allocation and distribution cannot be sustainable if fragmented by competition across scales and sectors;

(2) Management that treats different aspects of water, e.g., hydrological, ecological, and socioeconomic, separately, ignores their inherent interdependency, possibly at the expense of long term sustainability.

In this light, it is argued that Collaborative Adaptive Management (CAM) can help water resources managers to better address the influx of new and cumulative problems that arise from the unpredictable and complex nature of water systems. By combining the experiential and experimental dimensions of adaptive management with the vertical and horizontal dimensions of collaborative management, CAM can help managers face the daunting challenges that stem from the complexity, non-reducibility, and unpredictability of socio-ecological systems. CAM acknowledges the interdependent nature of society and ecology, thus increasing the likelihood that healthy, adaptive, and sustainable responses can be developed.

Addressing complex and "wicked" socio-ecological problems such as these with a "divide-and-conquer" approach is counterproductive and ignores the interdependent nature of complex adaptive water systems and the restoration projects needed to protect them. The excesses of power and dominion typically seen within traditional institutions in the water sector do not foster sustainable or inclusive solutions; indeed, the era of bureaucratic administrations serving as the 'final arbiters' and master controllers of the system needs to come to an end. Today's multidimensional problems require multidimensional collaboration - amongst experts, managers, stakeholders, and the public at large. New social and physical realities demand not only a more integrated and adaptive paradigm of management, but also an overall shift toward collaborative problem solving. Adaptive co-management, or collaborative adaptive management (CAM), speaks to this need by adopting a more holistic approach to solving the multidimensional problems inherent within water resources management and restoration. CAM recognizes that for any water management solution to be durable, transparent, and accepted, it must be capable of charting courses where uncertainty is high and stakeholder interests are varied.

Although CAM is a very promising approach to allow for more effective water governance and management by focusing on composite rather than piecemeal solutions and relying on a combination of inductive and deductive reasoning, Engle et al. (2011) stress the importance of reconsidering critical elements of integrated and decentralizing approaches to water management if the aim is to create a synergy by combining such approaches with co-management and AM of water resources. These authors highlight, for example, that "integrated water management regimes with certain elements of centralized command and control may be more adaptive and flexible at the expense of democratization and participation" and that "the implementation of integrated water management approaches, and before that command and control institutions, established mechanisms, structures, and processes may constrain the transition of water management into a new framework that is both integrated and adaptive".

This paper is aimed to offer some reflections on the subject of managing water related issues and their practical complexities that are primarily based on literature as well as personal experiences and observations of the first author. Similarly, the exploring cases provided in this paper aim to offer the reader narratives of challenges, successes as well as some lessons learned from these practical examples, and are not meant to offer evidence for propositions provided in this paper. In this light, this exploring discussion paper is aimed to provide tacit knowledge and insights that may support to bridge the divide between theory and practice that can so often be observed with the implementation of (new) approaches to water resources management.

\section{A New Class of Problems}

Today's water managers are confronted with a class of problems that is without precedent. To understand how these unprecedented new problems are affecting water managers, one need only look at the situation in Coastal Louisiana. The hurricane-stricken state represents a complex and interdependent problem in need of a collaborative and sustainable solution. Despite the availability of federal and state funds earmarked for restoration projects, Louisiana is losing a football field's length worth of wetlands every half hour (personal communication, Troy Constance, March, 2007; Coalition to Restore Coastal Louisiana, 2000). Since 2003, the US Army Corps of Engineers, in partnership with the State of Louisiana, have been actively pursuing solutions, initially under the Louisiana Coastal Area (LCA) Study followed by the State's 2007 Coastal Restoration and Protection Act. However their solutions have not addressed one of the fundamental issues: Mississippi River navigation (Barry, 1997). If a successful outcome is to be negotiated, then the needs of boat operators and navigators (who require stable water levels) must be balanced with those of the wetlands (that require changing amounts of water). The key question remains why, despite detailed analysis by peerless scholars and practitioners (Boesch et al., 2006), is the state still incapable of devising effective restoration solutions? 
The Missouri River is the longest river in the United States and often referred to as the "Big Muddy". According to the nonprofit conservation organization American Rivers, it is also the most endangered river in the country. The Missouri River operates within a straight-jacket of multiple and conflicting functions (e.g., water supply, flood protection, navigation, and hydropower), all of which are dictated by the river's Master Manual. The situation is complicated by the fact that the river flows through nine different states, each with their own set of diverse constituencies. And in the past thirty years, these constituencies have unfortunately been more prone to litigate than collaborate when their interests have conflicted.

In the past three years, however, some recommended steps have been taken to create a river-based, system-level organization of stakeholders that is firmly based on collaborative principles. Efforts targeting wildlife preservation have also been made, as seen by the attempts to apply technical adaptive management tools to the recovery of the pallid sturgeon and the piping plover (Light, 2009; National Research Council, 2002). Although symbols of progress, these responses still fall desperately short of what is needed to overcome the multidimensional and cumulative challenges being faced.

A look at the many other failed river related efforts in the U.S. and it becomes clear just how urgent the need is for a new approach to managing the nation's water resources. Examples of these shortcomings abound: the ongoing smelt operations within the San Francisco Bay/Delta; the salmon recovery efforts in the Columbia River; the struggle to save the silvery minnow of the Middle Rio Grande, and the efforts of the Red River of the North to reduce flooding and water quality impacts on Lake Winnipeg. Even the Everglades serves as a reflection of failed water resource management: it was decided to approach the issue of water supply from a "master plumbing" angle rather than advancing a more natural-flow regime, a regime that is essential in order to recover the Everglades' mosaic of ridges, sloughs, wet prairies, tree islands, and wetland complexes.

Most of the river-related infrastructures and waterways within the United States were built circa 1930-1960 and are in desperate need of redesign and replacement; they have exceeded their economic lives and the challenges listed above underscore this. Moreover, climate change and ongoing shifts in key environmental stressors (e.g. population growth, water availability, oil peaking) will continue to compound existing threats to water-related infrastructure over the next twenty to forty years. Both the yawning oscillations in weather patterns-as evidenced by the 1983-84 El Niňo event in South Florida (Light, Gunderson \& Holling, 1995)-and the unprecedented records of multi-year droughts in Cyprus (Adamowski \& Karapataki, 2010), signal a new physical reality that must be addressed.

Throughout the world, water availability and use, along with population growth and energy costs have become mega-drivers spawning "perfect storms" or negative synergies. Myers (1995), one of the founders of the biodiversity movement, was the first to report on this emergent phenomenon. Kates and Clark (1996) expect the number of surprises (including expressions of negative synergies) to double worldwide by 2025. On both a regional and international level, water resource systems have become increasingly vulnerable to many multi-dimensional surprises, which have allowed them to be swept into the vortex of convergence of multi-dimensional surprises of slow, moderate and rapid time steps at landscape scales, creating these negative synergies that threaten the collapse of social and ecological systems in which they are embedded. Haiti and Yemen are examples while more are in the making even if anticipatory action is begun.

In addition to Haiti and Yemen, Africa is another area struggling to overcome its escalating water problems. Amidst the turbulence that grips most of Africa, Kenya has been one of the few mainstays of democracy and stability on the continent; it is also a country lauded for its historic efforts to preserve biodiversity within its national parks and wildlife preserves. Unfortunately, Kenya is not exempt from feeling the consequences of poor water resource management. The nation continues to suffer through a debilitating drought in its north and northwestern regions-one that has been attributed to long-term shifts in weather patterns. Meanwhile, staggering population growth in recent decades has forced average Kenyans to take extraordinary measures to protect their water supplies. The consequences have been widespread: even shepherds have resorted to carrying automatic assault weapons in order to ensure that their flocks have access to the rapidly diminishing water sources. The Kenyan government has responded in part by relocating rural communities away from crucial urban water supply catchment areas where deforestation and land alteration for food production are reducing annual water yields.

Closer to home, the aftermath of Hurricanes Katrina and Rita revealed many of the same dynamics with water resources playing a major role in the unfolding of a much more perilous situation. The level of destruction caused by Hurricane Katrina could have been reduced had the infrastructures governing Coastal Louisiana's waterways not been in such poor condition. The state's flawed approach toward navigation and flood control was 
exposed when unusual climatic conditions in 2005 triggered a tragedy far beyond most people's expectations. Indeed the question still remains, "How could this have happened in a developed country such as the United States?" Part of the answer is found in the piecemeal approach to levee construction and maintenance that had evolved in response to the erratic pattern of Congressional appropriations. Coastal Louisiana's natural defenses (e.g. ridges and sloughs that buffered New Orleans) had also slowly been collapsing over decades. The two issues combined made an already-destructive hurricane that much more lethal.

The aftermath of the 2005 storms is still being felt by Louisianans today. Hurricane Katrina peeled back the thin veneer of civilization that had been covering a troubled city. To the casual observer, New Orleans is a national treasure that is globally recognized for its distinct culture, music, art, and Mardi Gras celebrations. Despite this colorful reputation, the community's basic day-to-day needs have been historically abused and neglected. Katrina revealed the structural fissures that had been developing over the years within the city, as evidenced by the deplorable conditions of its hospitals, the neglect of the levee system, and the incapacity of the police, fire, and emergency rescue teams to perform their duties. The world watched as the U.S. National Guard came to help a city that could not help itself. And although Kenya and Coastal Louisiana are separated by more than an ocean, and encompass very different societal orders, similar environmental stressors and negative, self-reinforcing dynamics were-and still are-at work.

These are examples of wicked problems; problems that Ludwig (2001) argues have no solution because current methods of management are incapable of solving them. Part of the struggle is that these problems have no definitive formulation, nor any apparent end point. Such multi-dimensional ills, including the imperative of ecological restoration, have no authoritative expert or answer to which to turn. This paper argues that the traditional concept of water managers and their respective institutions as "controllers of the reins of the system", or as the "final arbiters" of disputes, is outdated and that attention needs to be shifted to underlying assumptions and conflicts in societal and agency values and missions. The power of dominion and its commanding efficiencies of bureaucratic administrations in governing espoused by Webber (1904), and the means by which to maintain dominion through deceit, despotism, and political manipulation championed by Machiavelli (1998), are the bases by which nation states were pulled out of feudalism.

The time has come to combat these excesses of power and dominion with the emergence of a new social reality (Ehrlich, 2009), one that is marked by post-sovereign governance (Karkkainen, 2000) and the power of collaborative problem solving. This will unleash the force of relationship for the commonwealth (Mesle, 2008) and help civilization come to grips with these wicked problems that give sustenance to C. S. Holling's (1982) observation that "man appears to have forgotten where he comes from and has lost sense of where he is going."

\subsection{To Control or Adapt?}

The literature on adaptive management (e.g. Gunderson, Holling, \& Light, 1995; Lee, 1999; Gunderson \& Holling, 2002; Pahl-Wostl, 2007) and collaborative management (e.g. Wondolleck \& Yaffee, 2000) describes the type of multidimensional challenges inherent in the management of social-ecological systems such as watersheds. The concepts of adaptive management and collaborative management have recently been converging into the concept of "adaptive co-management" or "collaborative adaptive management" (e.g. Olsson et al., 2004; Armitage et al., 2007; Huitema et al., 2009). Restoration leaders are discovering that the most viable options are those that help us learn new ways of responding to seemingly intractable technical and social problems (Armitage et al., 2009; Kallis et al., 2009; Huitema et al., 2009). Collaborative Adaptive Management (CAM), links both the experiential and experimental learning dimensions of adaptive management with the vertical and horizontal dimensions of collaborative management, and is aimed at improving our understanding of, and ability to respond to, complex social-ecological systems (Armitage et al., 2009). It is argued that this approach should be more frequently leveraged when devising sustainable solutions to interdependent water resources problems.

Collaborative management emphasizes the sharing of rights, responsibilities, and power between different levels and sectors of government and civil society (Huitema et al., 2009), whereas adaptive management (informed by iterative learning about the social-ecological systems and earlier management successes and failures) increases resilience. Experimentation refers to the "probing" of that system which is being managed and the monitoring the system's responses to interventions. Scholz and Stiftel (2005) state that CAM involves the "evolution of new governance institutions capable of generating long-term, sustainable policy solutions to wicked problems through coordinated efforts involving previously independent systems of users, knowledge, authorities, and organized interests."

CAM is not a panacea for all water resources problems involving environmental restoration efforts, and will not be appropriate in all cases (Armitage et al., 2009). However, it can be viewed as a very useful tool in a suite of 
options to help govern and manage social-ecological systems and restoration efforts that are plagued by uncertainty and complexity. The aim of this paper is to explore the potential of CAM in propelling water resources management and restoration efforts forward in the face of uncertainty and complexity. Again, it is important to note the issue stressed by Engel et al. (2011) that more in-depth research is needed in order to understand the differential abilities of water management regimes to incorporate adaptive approaches to water management due to the diversity of implementation models, as well as the maturity of the water management system in its level of decentralization and integration. Their Brazil case study, in fact, indicates that AM may thrive most when long-term environmental sustainability is prioritized over equity through the representation of a wider group of stakeholder interests.

\subsection{Divide and Conquer?}

Conventional methods and competencies typically dissect large, complex ecological problems into smaller pieces, while assuming that they can be made more tractable and solvable if a "divide and conquer" strategy is used. Breaking down a problem into its various components and solving each part may seem more practical in theory, but may in fact lead to partial solutions. These partial solutions are problematic because they often lack acceptance by the public and their representatives and fail to meet the multiple and conflicting functions requisite to water management, while ignoring both the high degree of interdependence among the key parts of a restoration or watershed management plan, as well as the feedbacks between the socio-economic and physical components of complex adaptive systems such as watersheds. Optimizing subsystems (e.g., irrigation diversions) or individual functions (e.g., navigation), sub-optimizes the whole. For example, until navigation is fully integrated into restoration and protection in Coastal Louisiana, there will be no durable solutions. Solving the multi-dimensionality of "wholes" at the system-level (Gell-Mann, 2001) requires not only addressing the "parts", but also a redesign of the requisite functions in ways that service the whole (as composites) that is greater than the sum of its parts.

The sediment of the Mississippi River, for example, is dominated by navigation needs, however the delta is sediment starved. As Rising Tide (1998) unassailably documents-sediment management is fundamentally a social-cultural and political problem. In the Kissimmee River Restoration Program (KRRP) that began in 1985, the project team planners ignored the legacy of political boundaries and artifacts of accepted but untested precedents and focused on ecosystem form and function rather than individual elements. The design team developed three holistic (i.e. composite) solutions (Walters, Gunderson, \& Holling, 1992) that managed to perform multiple functions (i.e. water supply, flood control, navigation, sports fishing and ecological restoration) while simultaneously satisfying a diverse group of constituents. These solutions were embedded in the hydrological determinants of ecological integrity for the lower Kissimmee Basin. The project team and its counterparts in the federal, state and non-profit sectors were largely successful because there were no rules to follow. No one had ever restored a river before, so problems were uncovered and progress toward fitting solutions were designed in collaboration with the various constituents, and technical and scientific experts.

\subsection{From Pieces to Composites}

Solving some or all of the components of complex water resources problems involving ecological restoration is sometimes like "optimizing" the parts. However, this collective of "optimized parts" often fails to realize the intent of ecosystem level restoration actions. Because of the interdependence of landscape dynamics, changes in one-function produces a direct change to that feature and most likely will cause changes to other functions. It was thought that restoration of the Kissimmee River regime would devalue the sports fishing industry, but in fact the opposite happened. The high quality fishing areas along the channel were actually remnants of the old meanders.

CAM is a science based, iterative, and inductive learning approach that considers some or all of the components of a project while also respecting the ways in which the new composite functions may be changed. Adaptive management, also referred to as 'learning by doing', is based on 'a more inductive approach of deriving insights from new information' where 'dynamic hypotheses guide reasoning and structured argumentation' (Pahl-Wostl 2007). Collaborative processes are generally represented as cyclical, and can be characterized as 'highly iterative and nonlinear' (Ansell \& Gash, 2007). Combining both adaptive and collaborative approaches to managing and solving interdependent water resources problems meets the challenges that external influences and stressors require. It is based on the proposition that responsive, durable and authentic solutions require mending and weaving of strategic relationships (economic, ecological and social) in ways that can be mutually beneficial and reinforcing. In essence, ecological recovery and restoration efforts are able to function as Archimedes' "levers" 
that invariably put all the water resource related puzzle pieces (i.e. functions and purpose) into play for eventual reconfiguration.

\subsection{Familiar Patterns from Previous Experience?}

The business world generally understands the value of an analysis and system that focuses on optimization versus maximization of individual objectives. Various commercial enterprises, such as discount retail stores, rely on optimization to maximize profits; they realize that aggregate profits made on sold merchandise is more important than the profit made on each individual item. A similar approach is used within the construction industry. Known as "unbalanced bidding", many builders will mark up certain high-volume units in order to achieve greater profits while pricing other items in a way that little or no profit is made. In both scenarios, the full power of making tradeoffs among the component parts in order to achieve an overall "greater good" is evident. CAM makes use of this approach and applies it to water resources management and restoration efforts. It helps leaders arrive at solutions to ecological restoration problems, while also addressing the complex societal problems embedded within these restoration processes. Solving problems in this way has a higher degree of success at tendering a long-term, predictable, and stable solution.

Optimizing the overall enterprise-whether in business or ecological restoration-requires allocation judgments involving competing budgetary claims. Some economists (Stakiv, et al., 2001) believe that ecological benefits can be traded off against competing claims. Yes, there is a "balancing" judgment coupled with the optimization for ecological restoration, but "habitat units" do not allow for robust and viable ecosystems. The design team in the KRRP prepared three composite solutions, which met ecological criteria at differing levels of budget allocations. Cost/benefit analysis for ecological restoration assumes implicitly that "incremental" units can be traded off. Not so: the design team for the KRRP made it known that failure to authorize one of the three composite designs would result in a recommendation of "no action". However, ecosystem structure and function does not come in "halves" or "quarters" but in "whole" forms, as Nature herself intended.

\section{How can Leaders Address Obstacles and Progress in Complex Settings?}

Progress (Note 1) is the leader's end game (Note 2). Constructive action requires identifying and overcoming those obstacles (Note 3) that may threaten progress. Obstacles, as well as methods to overcome them, are varied and numerous. The most intractable problems are typically fraught with uncertainties, complexities, and have multiple dimensions. Each is addressed below:

\subsection{Navigating on Uncertain Seas}

In most ecological restoration efforts, there are no absolute answers; institutional experts are not always capable of solving all "problems", especially when differences of opinion are unavoidable and competencies are limited. Although well-intentioned, when tactical applications of solutions are applied in excessive and piecemeal ways, they may do more harm than good. These sorts of applications run the risk of oversimplifying the societal and scientific elements of the problem/issue. Furthermore, it is dangerous to assume that just because a certain method helped solve one problem that it will solve another. Tools must fit the problem and not vice versa. CAM is a method of problem solving that can succeed where other methods fail by looking at each ecological restoration effort uniquely and melding scientific solutions with the dynamic of society's values. Uncertainty is a natural part of a restoration project; the physical, biological and human aspects of such projects are often unique and generally not well understood.

For navigating on the high seas of uncertainty, CAM takes a science-based approach that structures problems as hypotheses, assumptions, and approaches upon which action is based. CAM pays specific attention to how "answers" are designed so that weaknesses in methods and approaches can be understood, communicated, and if possible, avoided. Uncertainties currently take the form of questions such as: "we don't know how to do this", "we don't understand how this and that affect each other", or "if we do this, what will happen...will it make things better (progress) or make things worse; fall back to a previous or worse condition?" Uncertainty in this form-encourages scientists to model in search of the "right" approach while forgetting that the nature of some uncertainties cannot be effectively overcome without jeopardizing the support for the effort. Also, some stakeholders rely on this quest to eliminate uncertainty because the status quo may be more comfortable to them. The result may be gridlock. The risks associated with restoration progress may be perceived as harming their interests. CAM cannot eliminate uncertainties but it can be a way to address them without jeopardizing public support. It may also provide a way forward that sufficiently satisfies stakeholders' fears, thus preventing their concerns from materializing into objections. 


\subsection{Complexity}

Complexity marked by both emergence and multiple causality, is sometimes mixed in with uncertainty. Complexity generally arises when there are many overlapping features whose cause-and-effect relationships are poorly understood. Ecological restoration sciences are already rich in complexity; one must add to this the ever-changing dynamics of the natural, social, and political factors and their context in restoration. Often this dynamic unfolds over many years marked in decades or generations. This three-dimensional nature of complexity (man's application of science, the natural dynamics of the landscape, and the political/social environment) can be faced more successfully if CAM is applied. CAM gives water managers and practitioners a possible means for unraveling the Gordian Knot of ecosystem restoration complexity.

\subsection{The Curse of Dimensionality}

The term multidimensional encompasses aspects of both time and space. The most challenging problems encountered in restoration science are a result of this multidimensionality. Temporally, complex problems may manifest themselves into different component parts over different time periods (analogous to "shape-shifting"); they may also change (get better, worse, more complex) with time, or present diminished solution opportunities in the future. Spatially, problems may spread to other areas over time, migrate entirely to other areas, be influenced by adjoining areas, or complicated by differences among geo-political units. Stakeholders often add to the multidimensionality of a problem by introducing diverse views, experiences, missions, visions, and goals. These issues, among others, create special challenges that make the problem more complex, and thus often more difficult to solve. However, applying CAM can help water managers untangle complicated situations and use the aforementioned diversity to their benefit. CAM identifies the multi-dimensional features of a restoration effort and adjusts as changes to these dimensional dynamics warrant. For example, the hydrologic regime of Lake Okeechobee in Florida was dramatically affected by the 1983-84 El Niňo event. During this climatic abnormality, the Lake's water levels fluctuated drastically: they reached historic lows followed by historic highs, all the while changing people's perceptions of water management and creating a natural experiment that put water deliveries in the spotlight. Instead of following a contrived schedule of monthly "slugs of water" proposed by Stan Caine (Assistant Secretary for Water and Science, U.S. Department of Interior), based on the results of the natural experiment to improve flows to the Everglades National Park, a rainfall-driven approach was adopted that was subsequently codified in federal statute as the "experimental deliveries program".

\subsection{Making Headway}

Adaptive Management (AM) offers leaders a tool box full of principles, methods and approaches to solve many water resource-related problems:

- Systems Analysis (Holling, 1966)

- $\quad$ Optimization (Walters \& Hilborn, 1978)

- $\quad$ Policy Sciences (Clark, Jones, \& Holling, 1979)

- Decision Analysis (Raiffa, 1970; Hilborn \& Walters, 1992)

- $\quad$ Strong Inference (Hilborn \& Mangel, 1997)

- Bounded Rationality and Induction (Arthur, 1994)

- Learning and Cognition (Argyris \& Schön, 1978; Roling \& Jiggins, 2000)

- Dynamic Simulation of multi-dimensional landscape level problems (Walters, Gunderson \& Holling, 1992) and marine aquatic systems (Walters et al., 2005)

- Alternative designs, tools and methods for Adaptive Inquiry and resolving uncertainties in forest and watershed problems (Vera Sit \& Brenda Taylor, 1998; Anderson et al., 2001)

- Conceptual Ecological Modeling (Ogden et al., 2005)

One of the fundamental contributions of AM thinking to strategy formation by Ralph Häfele (1974) is the concept of hypotheticality, which has been overlooked with respect to charting courses where uncertainty is high, risks of policy failure could be calamitous, and adaptive policy design may appropriately be fashioned. The challenge that all adaptive policy designs face is the irreducible risk of taking collective action in the face of the unknown or indeterminacy (i.e., increasing probability and cost of policy failure $\left.\left(\mathrm{P}_{1}-\mathrm{P}_{3}\right)\right)$. This is a strategic form of adaptive policy analysis drawing from a diversity of case examples that complements the more decision-specific approach (Hilborn \& Walters, 1992). 
At one end of the policy spectrum are safe-to-fail strategies that maximize resilience, and minimize risk of failure at the potential cost of reward. In the case of the Upper Red Lake walleye fishery the safe-to-fail strategy was ignored, exposing the fisheries to collapse with significant economic loss (Note 4). The Upper Red Lake walleye fishery that was owned by the Red Lake Band of Chippewa and operated by the Department of Interior since 1917 experienced a collapse in the mid-1990s from over harvesting The Band assumed leadership in 1997, and with the help of the Minnesota Department of Natural Resources, developed a recovery program. A total of 105 million walleye fry were stocked in the Red Lakes in 1999, 2001, and 2003. These efforts resulted in the three largest walleye year classes in at least 15 years (Rivers, 2006). When the cost and probability of policy failure exceed safe-to-fail, a "learning by doing" strategy may be prudent. Here policy-as-hypothesis - e.g., environmental studies (Schwarz, 2003), natural experiments, active or passive adaptive approaches, or evolutionary decision making (Anderson et al., 2001)-is coupled with monitoring and assessment to chart subsequent policy course corrections with the intent of steering clear of instability zones.

Only decisive action by the Band of Chippewa averted the loss of the Red Lake commercial walleye fishery. Unfortunately, this was not the case for Newfoundland, Canada when it's once prolific 400-year commercial cod fishery collapsed due to heavy fishing during the 1960-1970s. The precipitous and irretrievable collapse of this world-renowned fishery over the course of 25 years illustrates how quickly instability zones can be entered. The unbridled power of economic forces also increased the probability of policy failure in this case, and managed to transform a once-resilient system into a degraded and broken state. From the collapse of the Newfoundland cod fishery, Walters and Maguire (1996) identified several science-based stock assessment lessons that contributed to policy failure:

(1) Assessment errors can contribute to overfishing through optimistic long-term forecasts leading to the build-up of overcapacity [of the fishing fleet] or through optimistic assessments which lead to harvest levels being set higher than they should;

(2) Stock size overestimation is a major risk when commercial catch per effort is used as an abundance trend index, so there is continued need to invest in survey indices of abundance trend no matter what assessment methodology is used; and

(3) The risk of recruitment overfishing exists and may be high even for very fecund species like cod.

Walters et al. (2005) used Ecosim (a sophisticated modeling platform for exploring the dynamics of marine aquatic systems) to consider changes driven by some factor "outside" the breadth of factors considered in the stock assessment models (Note 5) reflected in Walters and Maguire's (1996) observations above. After successfully calibrating Ecosim to a number of time-series data sets, they demonstrated that:

“...widespread application of single-species MSY policies would in general cause severe deterioration in ecosystem structure, in particular the loss of top predator species. This supports the long-established practice in fisheries management of protecting at least some smaller "forage" species specifically for their value in supporting larger piscivores."

This analysis is one example of how policy designs can be made more robust to failure as ecological assessments are enhanced to capture critical aspects of scientific understanding.

In the devastating example of the Newfoundland cod fishery, it becomes clear how resilience can be squeezed out of what is supposed to be a safe-to-fail policy. At the opposite end of the spectrum are fail-safe solutions that, by their nature, lack resilience. Häfele (1974) referred to this policy option as "hypotheticality," in which the cost of failure exceeds society's willingness and/or capacity to tolerate. A nuclear physicist by training, Häfele was anticipating eventualities like Chernobyl, Three Mile Island, and groundwater contamination at the Hanford Nuclear Reservation (Note 6).

Many water resources solutions in the past have been based on "fail-safe" solutions where control and redundancy for safety sake are applied to reduce but never eliminate the potential for catastrophic failure. Humanity's track record for "fail-safe" solutions is mixed at best and has always been conditioned by human error and the unknown (Schrader-Frechette, 1993). With the variability and intensity of weather events extending beyond established periods of record, consulting companies in water resources are beginning to place more attention on the liability associated with certifying a given level of protection associated with storm water or flood control projects. Rediscovering ways to let rivers roam again and non-structural alternatives offer more safe-to-fail alternatives to increasing flood control structures along river banks that render all other upstream and downstream structures less effective. 
A country that has been actively rediscovering and inventing new responses to such weather-related phenomena is the Netherlands. In response to rising sea levels, shifts in water storage and runoff patterns from the Alps, and greater implications for flooding, the Dutch have embarked on what is referred to as a " 180 " degree framework document (Ministry of Transport, Public Works and Water Management, 2000). They not only reversed many of the science and engineering traditions for which they are known, but also began changing their 400 -year perception of water as the enemy or victim (A Different Approach to Water, 2004). In its simplest description, the Dutch government is literally altering the land to accommodate water and nature. In this way, the most densely populated industrialized nation on the planet is taking steps to increase its resilience to and reduce its reliance on fail-safe solutions. Although this is being done in anticipation of future changes that appear inevitable, the Dutch are also making a statement to the world regarding the need for a new societal response to such human predicaments.

However, as the future departs in radical ways from the past, learning by experience becomes less reliable. The arrows of time and complexity are to a large extent irreversible, leaving us with fewer options than before. And despite all the ambitious efforts of the Dutch to reverse course, there is only so much land that can be turned into water before it threatens to displace their population based on experiences from the past. As the Dutch framework document illustrates, becoming future responsive will require increasing ingenuity, creativity, and shifts in cultural norms if current limits of experience and capacity are to be exceeded. It would appear that the problem of hypotheticality is growing as the risks and costs of policy increase, and that natural capital, not financial capital, has become the limiting factor to further human "growth" and development (Daly, 2005). Therefore, becoming future responsive will require us to gain "experience" by analyzing options in such a way that sophisticated conjectures about the future (Baskerville, 1979) may be developed.

\subsection{Embracing the Counter-Intuitive}

The new generation of scientific management ushered in by adaptive management (Walters \& Hilborn, 1978; Walters, 1986) relies predominantly on powers of observation (i.e., Bayesian approaches), experimentation (i.e., active and passive adaptive) and deduction (e.g., the powerful "engine of deduction," using dynamic simulation) Hilborn, Walters, \& Ludwig, 1995). However, Ludwig (2001) subsequently raised concerns that the extant approaches to "management" fall short of making headway posed by wicked problems. During the workshops at the International Institute of Applied Systems Analysis in Austria leading up to the publishing of Adaptive Environmental Assessment and Management (Holling et al., 1978) inquiries on concerns regarding hypotheticality (Häfele, 1974), the foreclosure of policy options (Walters, 1975), and the question of whether "one can anticipate non-probability events" (Clark \& Swain, 1975) were deliberated. When design problems carry a low probability (but high cost) of policy failure, the tactic taken by most nuclear reactor designers is to reduce risks to levels experienced by society as natural hazards (e.g., hurricanes, floods, earthquakes, etc.) based on the assumption that "fail-safe" solutions can never reduce risk to zero (Clark \& Swain, 1975).

This notion of anticipating exigencies beyond the realm of experience and non-probabilistic events that immerses decision makers in simulations of hypothetical situations was incorporated as a component of what Clark, Jones and Holling (1979) termed "Ecological Policy Design (EPD)". Extensive combing of the literature has failed to uncover further development of EPD as a distinct line of inquiry aside from the tradition established by Holling et al. (1978) and additional research around this topic is warranted.

In today's world, water resource decision makers are being asked to make more complicated decisions in less time-and with reduced trust on past experiences. Even with the ability to apply the most rigorous of assessments, the long-term consequences of climate change coupled with an increasing number of major environmental stressors (e.g., population growth, oil peaking, mass extinctions, limits to freshwater availability) are creating unique and unprecedented challenges for water managers. However, it can be argued that incorporating certain elements of EPD into a revised definition of CAM will help water managers combat these challenges. The application of both EPD and CAM are important because they help humans overcome the natural deficiencies they have in trying to solve complex problems that involve temporal discontinuities at multiple spatial scales (Gunderson, Holling, \& Light, 1995; Dörner, 1986, 1996).

To observation, experimentation and deduction, Arthur (1994) adds induction. There are two reasons why deductive reasoning breaks down and those two reasons are what attracted Arthur to the use of induction under conditions of complexity. First, beyond a certain level of complication, our capacity to reason breaks down. This is otherwise known as bounded rationality (Simon, 1956). Second, we cannot depend on the behavior of others to be predictable, so we are forced make conjectures about future behavior. The trap that the skeptic will ceaselessly point out is that this loss of deductive capacity throws reasoning into the land of subjective beliefs, 
the classic case being the "Black Swan" conundrum. The skeptic will never accept that all swans are white regardless of how many observations he makes that confirm the proposition.

Arthur argues that under conditions of ill-defined problems, humans look for patterns, and simplify them into mental models (a.k.a., schemata or hypotheses) of how the world works from which localized deductions and action are carried out. The results of action either confirm or weaken our beliefs in a given schemata. Mental models are discarded when they cease to perform, and are replaced with ones that will hopefully perform better. The result is inductive "leaps" of understanding, and adaptive behavior (Ashby, 1952, 1956) that helps us improve the efficacy of responses in the face of challenges that differ radically from previous experience. This iteration between induction and deduction in the service of effective action, form the "building blocks" for becoming future responsive.

Arguably, the line of reasoning developed by Clark, Jones and Holling (1979) that attempted to address questions raised by Clark and Swain (1975) has simply been ahead of its time and is in need to be revisited. Advances in understanding complex adaptive systems (Holland, 1998; Gell-Mann, 1994; Kauffmann 1995), cognitive learning (Maturana \& Varela, 1980; a.k.a., Santiago Theory of Cognition; Röling \& Jiggins, 2001) and induction (Arthur, 1994; Kelly, 1996) have affirmed their propositions.

\subsection{Getting There from Here}

The novel ideas captured by Clark et al. (1979) are beyond the scope of this paper. Suffice to say that creating sophisticated conjectures about the future based on "experience" designed in the present (Arthur et al., 2001; Scharmer, 2007), does not displace the deductive logic embedded in the scientific method; they complement each other. Converting "unknowns" into "knowns" requires both inductive and deductive reasoning. The coupling of inductive methods with deductive traditions accelerates the rate at which "unknowns" are converted to "knowns." This conversion rate yields both the small increments and quantum leaps in understanding, both of which are necessary if policies are to become more future responsive. Inductive reasoning can help fill in gaps in understanding and offer "useable ignorance (Note 7)" (Ravetz, 1986). By identifying environmental stressors, their potential synergetic effects and influence on policies under formation and their supporting infrastructure can be tested as "hypothetical configurations of relational reality" to increase the robustness of policies under active design.

\subsection{Why Collaboration?}

Diversity mirrors complexity and vice versa. Therefore, collaboration offers a diversity of perspectives that can provide water managers with the leverage they need to address multidimensional and complicated problems. Diverse perspectives generate a creative tension that, if properly managed, can create a platform for the emergence of novel solutions that no one expert or authoritative entity could come up with. Additionally, solutions to complex problems require unique and authentic solutions which native knowledge can contribute meaningfully to in terms of policy design. What is the alternative to collaborative risk taking in a world grown increasingly complex, uncertain and menacing? Wicked problems exist in a relational reality that can never be fully penetrated; however, if working in collaboration, diverse interests can create more sophisticated composite solutions than would be otherwise expected. Collaboration is also more likely to generate more robust alternative hypotheses worthy of rapid prototyping. In fact, geneticists, embryologists and theoretical biologists are documenting the evolutionary and developmental power of relationships. Gilbert et al. (2010) summarize recent studies in symbiosis by saying that symbiosis is not the exception, but the rule:

"Kauffman (1995) famously said that 'All evolution is coevolution'. The situation may actually be more intimate. Almost all development may be codevelopment. By codevelopment we refer to the ability of the cells of one species to assist the normal construction of the body of another species."

From a perspective of evolution, Gilbert et al. (2010) affirms Dawkins' (1989) proposition that the powers of relation are superior in "selective fitness" to the power of dominion. Not in the sense of fitness in a superior solitary organism, but more "fitting" or appropriate responses in the relational or symbiotic (not parasitic, but in a mutually beneficial way) reality which defines the domain of existence. Moreover, Dawkins applied the concept of neo-Darwinian genetics to human culture. Culture is a reliable conservative replicator that has survival value just as a gene. Genes are reliable conservative replicators that find their expression in phenotypes. The cultural equivalent of a gene, Dawkins argues, is a "meme" that finds its expression in the behavior of humans. Moreover, memes can replicate and adapt much faster than genes. In a penetrating critique of Dawkins' works, Hayle (1995) prefers to refer to "memes" as "cultural grand narratives". Hayle views Dawkins' body of work (e.g., The Selfish Gene and The Blind Watchmaker) as evidence that the "narrative of individualism" is being eclipsed by evolutionary narratives expressing a relational reality, featuring cooperation over competition. 
There is an increasing appreciation (Axelrod, 1984) and expansion in the use of cultural expressions of collaboration, as well as documentation of their potential for achieving "higher order stability" (Dawkins, 1989). Birkhoff (2003) analyzed public participation in water reuse projects in Texas, California, and Georgia and found that better decisions emerged when diverse knowledge, interests, and expertise were part of the decision-making process. When stakeholders were not fully involved in framing, developing, evaluating, and implementing solutions to complex public problems, they tried to find alternative ways to express and meet their interests, which hampered the decision process (Birkhoff, 2003).

\subsection{Pilot Testing, Demonstrations, Experiments}

Another problem solving technique includes the testing of ideas in controlled trials. CAM tests or experiments are meant to include statistically designed evaluations that follow scientific methods. Some phenomena that must be understood to advance progress may defy application of science methods and statistical design. For instance, the domain cannot be controlled well enough to meet science methods, or the test scenarios cannot be pre-determined or created to order. In these cases, rigorous forms of learning by doing, at "safe to fail" scales can yield valuable insights into how things work. This is a way of gaining knowledge that may allow conversion of "unknowns" to "knowns."

Complex problem solving requires (collaborative) monitoring, data collection, and analysis as a means to develop new knowledge. Sometimes, a structured analytic plan including simulation models during implementation may be required to convert an "unknown" to a "known". These tests may also satisfy the desire by the public to see incremental and on-the-ground progress towards ecological restoration.

\subsection{Leading the Learning}

The fourth leadership challenge requires monitoring and assessing the incremental changes that result from implementing newly-found knowledge and taking corrective measures, if warranted. Proper monitoring and assessment of the incremental change associated with restoration efforts will equip the leader with validation of the newly found knowledge. In the event some of the newly-found knowledge (understanding) fails to provide the improvements expected, monitoring and assessment would provide early detection and opportunity to re-cycle the new knowledge for fine-tuning and reapplication at a later date. Likewise, validating success in producing expected improvements should be documented and used as a resource for problem solving.

\subsection{Navigating Hidden Shoals and Whirlpools}

CAM simultaneously manages both conflict and uncertainty by fostering forums of science-based information and collaboration. To establish a foundation for successful CAM, serious efforts must be made to engage the government(s) that have jurisdiction over the respective water resource, and tribal and stakeholder interests must be addressed in order to minimize the likelihood for litigation, gridlock and diminished outcomes. Asymmetries in authority and power in complex problem solving has exacerbated mistrust and contention for decades. Lack of true collaboration not only yields sub-optimal ecological responses to applied scientific knowledge, but also can spell ruin by ignoring the importance of the human side of a restoration endeavor.

With appropriate incentives and thorough trust building, as well as greater support for progress among various interests, agencies will evolve. Collaboration requires more time and patience to develop; however more durable, scientifically sound and widely accepted results will come from the openness, transparency and accountability found in collaboration. At the same time, however, an optimum balance will need to be found to address the potential strain that Engel et al. (2011) discuss between water management theories and their implementation in practice, in particular combining integrated (participatory) and adaptive (flexible) approaches to water management. Although adaptive approaches to water management may appear to be a very suitable answer to dealing with increasing complexities and uncertainties, in reality, it may be challenging to accommodate the intended changes within the framework of previous and current management structures and transitions. In this light, a very recent study on integrated and adaptive governance of water resources in South Africa concludes that the features of integrated and adaptive water governance "comprise a number of synergies and trade-offs, which play out differently in different combinations and contexts" while outlining the need for further empirical research on such trade-offs as well as on "the appropriate degree of features such as participation, flexible institutions and redundancy” (Herrfahrdt-Pähle, 2012).

\section{Conclusion}

The new problems facing water managers today are interdependent, complex, and often unpredictable. This new class of problems is exacerbated by climate change, ageing waterway infrastructures, and outdated paradigms of institutional authority and bureaucratic power structures. Natural and man-made water resources systems provide 
a variety of services, but conventional management methods do not address the complexity and uncertainty surrounding their protection, maintenance, and design.

In this paper, the main features of CAM were discussed and some new concepts explored that may help to reframe CAM in a deeper, more robust, and transdisciplinary perspective, responsive to the unparalleled challenges facing water resources managers and policy makers. CAM, which combines the concepts of adaptive management and collaborative management, can help address the seemingly intractable technical, environmental and social problems inherent in complex social-ecological systems. It is a hybrid approach to problem solving that allows water managers to respond more effectively to the new physical and social realities of the 21 st century. With its 'ecosystem level' view of management and restoration, and belief in policy-as-hypothesis, CAM is an efficient way of managing both the high levels of conflict and uncertainty inherent in water resource management.

This paper presents several flexible and innovative ways to build on CAM by incorporating both old and new lines of cognitive and scientific reasoning. Some of the new concepts s discussed in this article include: focusing on composite solutions rather than 'divide and conquer' approaches to problem solving, avoiding instability zones in order to design sustainable policies, developing future responsive policies based on emergent understanding, using collaboration to generate more hypotheses worthy of rapid prototyping, and inclusion of the earlier-proposed but 'neglected' theory of Ecological Policy Design (Clark et al., 1979).

In fleshing out deeper dimensions of CAM and integrating new ones, the aim of this paper is to lengthen the stride in theory and practice as a means of protecting the capacity and integrity of our water resources. When water managers operate under conditions of complexity, deduction is a not a sufficient buffer to the influence of bounded rationality, subjectivity, and human conjectures about future behavior. In order to anticipate non-probability events and address wicked problems, rigorous forms of 'learning by doing' at 'safe-to-ail' scales must be incorporated into management. The collapse of the Newfoundland cod fishery not only illustrates the devastating consequences that arise when the probability and cost of policy failure are not properly measured, but also exposes the dangers that arise from entering instability zones.

Despite rigorous assessments, anticipating non-probability events is a difficult task, and the challenge is compounded by the fact that today's water resource managers are being asked to make more complicated decisions in less time with reduced trust on past experience. In developing solutions to these problems, the idea of Ecological Policy Design is revisited as it relates to collective complex problem solving and the human tendency to simplify ill-defined problems into patterns, schemata, or hypotheses. In addition to stressing the power and logic of this largely-overlooked theory, the idea of 'emergent understanding' is also put forth in order to achieve effective action. By using both deduction and induction, emergent understanding fosters creative tension between constructing schemata and testing them; it also helps managers avoid instability zones and solve unpredictable and complex problems. When the past does not repeat itself (when new challenges differ radically from previous experience), deduction and induction unite to create inductive 'leaps' of understanding that result in more adaptive and future-responsive behaviors. This new line of reasoning is important because emergent understanding is the foundation upon which future-responsive policies should be built. Indeed, the advancements made in the past twenty years toward understanding complex adaptive systems, cognitive learning, and induction support this proposition, as well as the belief that collaboration is more likely to generate alternative hypotheses worthy of rapid prototyping.

Various global crises and case studies were referenced throughout the paper in order to illustrate and highlight the importance of these propositions. These include the shocking number of failed river-related restoration efforts throughout the United States, the collapse of the oldest, richest fishery on Earth (i.e., the Newfoundland cod fishery), the economic and social conflicts arising in Kenya due to drought conditions, the collapse of social order and loss of life in Coastal Louisiana due to Hurricane Katrina, the rise of unprecedented water crises and aridity levels in Cyprus, and the attempts by the Dutch to alter their land to accommodate rivers in order to reduce flood risk. We argue that adopting a more holistic, integrated, and collaborative approach to water management will provide the necessary protection and flexibility needed to create sustainable solutions to the new class of water resources problems that we face, and will do so in a way that decreases uncertainties without jeopardizing public support and societal values.

An enhanced definition of CAM such as the one proposed in this paper will help leaders develop more robust, long-term, and sustainable solutions to water resources management and restoration efforts. Composite solutions that use emergent understanding to overcome obstacles and deal with uncertainty show a greater depth of understanding and respect for the complex societal problems embedded within water management and policy 
formation. The ego has been removed from this approach, as it not only acknowledges and respects that uncertainties exist (instead of attempting to eliminate them), but also seeks to address them strategically so that public and stakeholder support is maintained. Water managers will increase their likelihood of designing more durable and transparent problem solving techniques with this approach.

\section{Acknowledgements}

This research was partially funded by the Cyprus Institute and an SSHRC Grant held by Jan Adamowski.

\section{References}

Adamowski, J., \& Karapataki, C. (2010). Comparison of multivariate regression and artificial neural networks for peak urban water demand forecasting: the evaluation of different ANN learning algorithms. Journal of Hydrologic Engineering, 15, 729-743. http://dx.doi.org/10.1061/(ASCE)HE.1943-5584.0000245

Anderson, J. L., Hilborn, R. W., Lackey, R. T., \& Ludwig, D. (2003). Watershed restoration - Adaptive decision making in the face of uncertainty. In R. C. Wissmar \& P. A. Bisson (Eds.), Strategies for Restoring River Ecosystems: Sources of Variability and Uncertainty in Natural and Managed Systems. American Fisheries Society. Bethesda, MD.

Armitage, D., Berkes, F., \& Doubleday, N. (2007). Adaptive co-management: Collaboration, learning and multilevel governance. Vancouver, British Columbia, Canada: UBC Press.

Armitage D. R., Plummer, R., Berkes, F., Arthur, R. I., Charles, A. T., Davidson, I. J., Diduck, A. P., ... Wollenberg, E. K. (2009). Adaptive co-management for social-ecological complexity. Frontiers in Ecology and the Environment, 7(2), 95-102. http://dx.doi.org/10.1890/070089

Arthur, W. B. (1994). Inductive Reasoning and Bounded Rationality. Paper delivered at the American Economic Association Annual Meeting, Session: Complexity of Economic Theory.

Arthur, W., Brian, J. D., Jaworski, J., Jung, M., Nonaka, I., Scharmer, O., \& Senge, P. (2000). Illuminating the Blind Spot: Leadership in the Context of Emerging Worlds. McKinsey-Society for organizational learning leadership project, Cambridge, MA.

Ashby, R. (1952). Design for a Brain. Oxford, UK: Wiley.

Ashby, R. (1956). An Introduction to Cybernetics. London, UK: Chapman and Hall.

Axelrod, R. (1984). The Evolution of Cooperation. New York, USA: Basic Books.

Barry, J. M. (1997). Rising Tide: The Great Mississippi River Flood and How it Changed America. Touchstone, NY, USA.

Birkhoff, J. (2003). Community conflict over water reuse. Perspectives from conflict analysis and resolution. In T. W. Hartley (Ed.), Water reuse. Understanding public perception and participation. Water Environment Research Foundation, Alexandria, Virginia, USA.

Boesch, D. F., Shabman L., Antle, L. G., Day, J. W., Dean, R. G., Galloway, G. E., Groat, C. G., ... Whigham, D. F. (2006). January 262006 Working group for post-hurricane planning for the Louisiana coast. A New Framework for Planning the Future of Coastal Louisiana after the Hurricanes of 2005, Maryland Center for Environmental Science, University of Maryland.

Bondanella, P. (1998). The Prince. Oxford, UK: Oxford University Press.

Clark, W. C., Jones, D. D., \& Holling, C. S. (1979). Lessons for ecological policy design: A case study of ecosystem management. Ecological Modelling, 7(1), 1-53. http://dx.doi.org/10.1016/0304-3800(79)90008-5

Clark, W. C., \& Swain, H. (1975). Hypotheticality, Resilience and Option Foreclosure: Summary Notes of an IIASA Workshop. IIASA Working Paper.

Coalition to Restore Coastal Louisiana. (2000). No Time to Lose: Facing the Future of Louisiana and the Crisis of Coastal Land Loss. Baton Rouge, Louisiana.

Daly, H. (2005). Economics in a full world. Scientific American, 293(3), 100-107. http://dx.doi.org/10.1109/EMR.2005.27010

Dawkins, R. (1989). The Selfish Gene. (New ed.). New York: Oxford University Press.

Dorner, D. (1986). Assessment of operative intelligence. Diagnostica, 32, 290-308.

Ehrlich, P. (2009). Cultural evolution and the human predicament. Trends in Ecology and Evolution, 24(8), 410-412. http://dx.doi.org/10.1016/j.tree.2009.03.015 
Engle, N. L., Johns, O. R., Lemos, M., \& Nelson, D. R. (2011). Integrated and adaptive management of water resources: tensions, legacies, and the next best thing. Ecology and Society, 16(1), 19. Retrieved from $\mathrm{http}: / / \mathrm{www} . e c o l o g y a n d s o c i e t y . o r g / v o l 16 /$ iss $1 /$ art19/

Gell-Mann, M. (1994). The Quark and the Jaguar: Adventures in the Simple and the Complex. UK: Little, Brown, and Company.

Gilbert, S. F., McDonald, E., Boyle, N., Buttino, N., Gyi, L., Mai, M., Prakash, N., \& Robinson, J. (2010). Symbiosis as a source of selectable epigenetic variation: taking the heat for the big guy. Proc. Royal Soc. Lond, 365, 371-378. http://dx.doi.org/10.1098/rstb.2009.0245

Gunderson, L. H., \& Holling, C. S. (2002). Panarchy: Understanding Transformations in Human and Natural Systems. Washington, D.C.: Island Press.

Gunderson, L. H., Holling, C. S., \& Light, S. S. (1995). Barriers and Bridges to the Renewal of Ecosystems and Institutions. New York: Columbia University Press.

Häfele, W. (1974). Hypotheticality and the new challenges: The pathfinder role of nuclear energy. Minerva, 3, 303-322. http://dx.doi.org/10.1007/BF01102526

Hayles, K. (1995). Narratives of evolution and the evolution of narratives. In J. L. Casti \& A. Karlqvist (Eds.), Cooperation and Conflict in General Evolutionary Processes. New York, NY: John Wiley and Sons.

Herrfahrdt-Pähle, E. (2012). Integrated and adaptive governance of water resources: the case of South Africa. Regional Environmental Change, 2012-Springer.

Hilborn, R., Walters, C. J., \& Ludwig, D. (1995). Sustainable exploitation of renewable resources. Annual Review of Ecology and Systematics, 26, 45-67. http://dx.doi.org/10.1146/annurev.es.26.110195.000401

Holling, C. S. (1966). The functional response of invertebrate predators to prey density. Mem. Entomol. Soc. Can. 48, 1-86. http://dx.doi.org/10.4039/entm9848fv

Holling, C. S. (1976). Myths of ecology and energy, in Future strategies of energy development: A question of scale. Oak Ridge Associated Universities, Oak Ridge, Tennesee, USA.

Holling, C. S. (1978). Adaptive Environmental Assessment and Management. Wiley, New York: International Institute for Applied Systems Analysis.

Holling, C. S. (1980). Forest insects, forest fires and resilience, in Fire Regimes and Ecosystem Properties. In H. Mooney, J. M. Bonnicksen, N. L. Christensen, J. E. Lotan, \& W. A. Reiners (Eds.), USDA Forest Service General Technical Report.

Holling, C. S. (1982). Predicting the unpredictable: Is it possible to identify the variable that triggers surprise and change? UNESCO Courier, 60-62.

Holling, C. S. (1998). Two cultures of ecology. Conservation Ecology, 2(2), 4. Retrieved from http://www.consecol.org/vol2/iss2/art4/

Huitema, D., Mostert, E., Egas, W., Moellenkamp, S., Pahl-Wostl, C., \& Yalcin, R. (2009). Adaptive water governance: Assessing the institutional prescriptions of adaptive co-management from a governance perspective and defining a research agenda. Ecology and Society, 14(1), 26.

Kallis, G., Kiparsky, M., \& Norgaard, R. (2009). Collaborative governance and adaptive management: Lessons from California's CALFED water program. Environmental Science and Policy, 12, 631-643. http://dx.doi.org/10.1016/j.envsci.2009.07.002

Kates, R. W., \& Clark, W. C. (1996). Expecting the unexpected. Environment, 38, 28-34. http://dx.doi.org/10.1080/00139157.1996.9933458

Karkkainen, B. C., Fung, A., \& Sabel, C. (2000). After backyard environmentalism: Toward a performance-based regime of environmental regulation. American Behavioral Scientist, 44(4), 690-709. http://dx.doi.org/10.1177/00027640021956332

Kauffman, S. (1995). At Home in the Universe: The Search for the Laws of Self Organization and Complexity London. Oxford University Press.

Kelly, K. (1996). The Logic of Reliable Inquiry. Oxford, UK: Oxford University Press.

Light, S. S. (2009). Assessment of adaptive management standards of practice pertaining to the Missouri River recovery. Adaptive Strategies Inc. Report, St. Paul, MN. 
Ludwig, D., Mangel, M., \& Haddad, B. (2001). Ecology, conservation, and public policy. Annu. Rev. Ecol. Syst., 32, 481-517. http://dx.doi.org/10.1146/annurev.ecolsys.32.081501.114116

Maturana, H., \& Varela, F. J. (1980). Autopoiesis and cognition: The organization of the living. Reidel, Boston. http://dx.doi.org/10.1007/978-94-009-8947-4

Mesle, R. (2008). Process-Relational Philosophy: An Introduction to Alfred North Whitehead. Templeton Foundation Press, West Conshohocken, PA.

Ministry of Transportation, Public Works and Water Management. (2000). A New Approach to Water Management. Reinders Partners, Pim Reinders, The Hague, Netherlands.

Myers, N. (1995). Environmental unknowns. Science, 269, 358-360. http://dx.doi.org/10.1126/science.269.5222.358

National Research Council. (2002). The Missouri River Ecosystem: Exploring the Prospects for Recovery. Washington, DC: National Academies Press.

Ogden, J. C., Davis, S. M., Jacobs, K. J., Barnes, T., \& Fling, H. E. (2005). The use of conceptual ecological models to guide ecosystem restoration in South Florida. Wetlands, 25(4), 795-809. http://dx.doi.org/10.1672/0277-5212(2005)025[0795:TUOCEM]2.0.CO;2

Olsson, P., Folke, C., \& Berkes, F. (2004). Adaptive co-management for building resilience in social-ecological systems. Environmental Management, 34(10), 75-90.

Pahl-Wostl, C. (2007). The implications of complexity for integrated resources management. Environmental Modelling and Software, 22(5), 561-569. http://dx.doi.org/10.1016/j.envsoft.2005.12.024

Raiffa, H. (1970). Decision analysis - Introductory lectures on choices under uncertainty. Addison-Wesley.

Ritchey, T. (2007). Wicked Problems: Structuring Social Messes with Morphological Analysis. Swedish Morphological Society. Discussion Paper. November, 2007.

Rittel, H., \& Webber, M. (1973). Dilemmas in a general Theory of Planning. Policy Sciences, 4, 155-159. Elsevier Scientific Publishing, Amsterdam. http://dx.doi.org/10.1007/BF01405730

Rivers, E. (2006). Red Lake: Back to the Future. Minnesota Volunteer Magazine. St Paul, MN.

Röling, N., \& Jiggins, J. (2000). Agents in adaptive collaborative management: The logic of collective action. In L. E. Buck, C. C. Geisler, J. Schelhas, \& E. Wollenberg (Eds.), Biological Diversity: Balancing Interests Through Adaptive Collaborative Management. Boca Raton, FL: CRC Press.

Scharmer, O. C. (2007). Theory U: Leading from the Future as It Emerges. NY, USA: Kindle Edition.

Scholz, J. T., \& Stiftel, B. (2005). Adaptive Governance and Water Conflict: New Institutions for Collaborative Planning. Washington, DC: Resources for the Future.

Schrader-Frechette, K. S. (1993). Burying Uncertainty. Risk and the Case against Geological Disposal of Nuclear Waste. Berkeley, USA: University of California Press.

Schwarz, A. (2003). The Impact of State Capacity on Enforcement of Environmental Policies: The Case of China. The Journal of Environment and Development, 12(10), 50-81. http://dx.doi.org/10.1177/1070496502250438

Simon, H. (1956). A comparison of game theory and learning theory. Psychometrika, 21(3), 267-272. http://dx.doi.org/10.1007/BF02289136

Stakhiv, E., Cole, R., Scodari, P., \& Martin, L. (2001). White Paper on Improving Environmental Benefits Analysis. Working Draft. Institute for Water Resources, Alexandria, VA.

U.S. Army Corps of Engineers. (2003). Louisiana Coastal Area, LA - Ecosystem Restoration: Comprehensive Coastwide Ecosystem Restoration Study. U.S. Army Corps of Engineers. New Orleans, LA. Retrieved from http://www.crcl.org/lca_menu.htm

Walters, C. J., Christensen, V., Martell, S. J. \& Kitchell, J. F. (2005). Possible ecosystem impacts of applying MSY policies from single-species assessment. Journal of Marine Science, 62(3), 558-568. http://dx.doi.org/10.1016/j.icesjms.2004.12.005

Walters, C. J., Gunderson, L., \& Holling, C. S. (1992). Experimental policies for water management in the Everglades. Ecological Applications, 2, 189-202. http://dx.doi.org/10.2307/1941775

Walters, C. J., \& Hilborn, R. (1978). Ecological optimization and adaptive management. Annual Review of Ecology and Systematics, 8, 157-188. http://dx.doi.org/10.1146/annurev.es.09.110178.001105 
Walters, C. J., \& Maguire, J. J. (1996). Lessons for stock assessment from the northern cod collapse. Reviews of Fish Biology and Fisheries, 6, 125-137. http://dx.doi.org/10.1007/BF00182340

Weber, M. (1904). The Protestant Ethic and "The Spirit of Capitalism". Translated by P. Baehr \& G. C. Wells. Penguin Books, 2002.

Wondolleck, J. M., \& Yaffee, L. (2000). Making Collaboration Work. Washington, DC: Island Press.

\section{Notes}

Note 1. Progress: changing the way we think and act, always moving to a higher order of development or evolution.

Note 2. Endgame: represents the final and decisive action. The counter-intuitive is that teaching master's chess, one starts with alternative configurations of the endgame and works backwards to develop patterns of moves that result in successful end results. Design is distinctive from "planning" in this regard. Planning starts with defining the problem and logically progresses to a "preferred alternative."

Note 3. Obstacles: problems, setbacks, challenges, crises, adversity, cascades of adversity...

Note 4. In 2009, the band harvested about 400,000 pounds of walleye of its quota of 820,000 pounds which it sold to Twin City restaurateurs. From "hook-and-line" commercial fishing the Red Lake band received \$1.75 a pound.

Note 5. A significant departure from the Hilborn and Walters position (Hilborn \& Walters, 1992) which concluded: "We believe the food web modeling approach is hopeless as an aid to formulating management advice; the number of parameters and assumptions required are enormous."

Note 6. The weapons production reactors were decommissioned at the end of the Cold War, but the manufacturing process left behind 53 million U.S. gallons $\left(204,000 \mathrm{~m}^{3}\right)$ of high-level radioactive waste that remains at the site. Washington Department of Ecology. Retrieved January 19, 2010, from http://web.archive.org/web/20080624232748/http://www.ecy.wa.gov/features/hanford/hanfordfacts.html

Note 7. Residual distinctions that are appreciated but not fully understood, which may open new and productive veins of inquiry in the future. 